\title{
Adubação fosfatada na cultura da soja na microrregião do Alto Médio Gurguéia ${ }^{1}$
}

\author{
Phosphorus fertilization in the soybean crop at the micro region of Alto Médio \\ Gurguéia
}

\author{
Francisco de Alcântara Neto ${ }^{2 *}$, Geraldo de Amaral Gravina ${ }^{3}$, Nara Oliveira Silva Souza ${ }^{4}$ Antônio Aécio de \\ Carvalho Bezerra ${ }^{5}$
}

\begin{abstract}
Resumo - O objetivo deste trabalho foi avaliar algumas características biométricas e o rendimento de grãos de soja, cultivada em solo com baixo teor de fósforo e submetida a diferentes níveis de adubação fosfatada. Foi instalado um experimento no município de Gilbués-PI, na microrregião do Alto Médio Gurguéia, no Sul do Estado do Piauí, no período de dezembro de 2007 a abril de 2008, em um Latossolo Amarelo. O delineamento experimental utilizado foi o de blocos casualizados, sendo os tratamentos constituídos por seis doses de fósforo $\left(0 ; 40 ; 60 ; 100 ; 120\right.$ e $\left.140 \mathrm{~kg} \mathrm{ha}^{-1} \mathrm{de}_{2} \mathrm{O}_{5}\right)$ com quatro repetições. Foram avaliados três caracteres: altura de plantas, altura de inserção da primeira vagem e rendimento de grãos. As doses de fósforo influenciaram de forma quadrática a altura das plantas, sendo que a altura máxima estimada foi de $56,69 \mathrm{~cm}$, obtida com a dose de 95,60 kg ha-1 de $\mathrm{P}_{2} \mathrm{O}_{5}$. A altura de inserção da primeira vagem não respondeu à adubação fosfatada e sua média foi estimada em 10,64 cm. Houve resposta quadrática da produtividade de grãos às doses de fósforo, sendo que o rendimento máximo estimado foi de $2.614,7 \mathrm{~kg}$ de grãos de soja para a dose de $94,8 \mathrm{~kg} \mathrm{ha}^{-1}$ de $\mathrm{P}_{2} \mathrm{O}_{5}$.
\end{abstract}

Palavras-chave - Cerrado. Glycine max. Rendimento de grãos.

\begin{abstract}
The objective of this work was to evaluate some biometric characteristics and the soybean grain yield, cultivated in a soil with low content of phosphorus and submitted to different rates of phosphorus fertilization. The experiment was located in Gilbués-PI, South of the Piauí state, from December 2007 until April 2008, in an Oxisoil. The experiment followed a randomized blocks design, with the treatments arranged as six doses of phosphorus $\left(0 ; 40 ; 60 ; 100 ; 120\right.$ and $140 \mathrm{~kg} \mathrm{ha}^{-1}$ of $\left.\mathrm{P}_{2} \mathrm{O}_{5}\right)$ with four replications. It was evaluated the height of plants, height of first pod insertion and the grain yield. The levels of $\mathrm{P}$ had influenced as a quadratic response the height of the plants, being the maximum height estimated as $56.69 \mathrm{~cm}$ for the quantity of $95.60 \mathrm{~kg} \mathrm{ha}^{-1}$ of $\mathrm{P}_{2} \mathrm{O}_{5}$. The height of insertion of the first soybean pod was had not influenced by the $\mathrm{P}$ fertilization and had a mean estimated as $10.64 \mathrm{~cm}$. A quadratic response of the grains productivity to the rates of $\mathrm{P}$ was observed, being the maximum productivity estimated as $2.614 .7 \mathrm{~kg}$ of grains of soybean for $94.8 \mathrm{~kg} \mathrm{ha}^{-1}$ of $\mathrm{P}_{2} \mathrm{O}_{5}$.
\end{abstract}

Key words - Cerrado. Glycine max. Grain yield.

\footnotetext{
* Autor para correspondência

${ }^{1}$ Recebido para publicação em 10/03/2009; aprovado em 23/03/2010

Pesquisa financiada pela Fazenda São Marcos

2Departamento de Agronomia, CPCE/UFPI, Bom Jesus-PI, Brasil, fneto@ufpi.edu.br

${ }^{3}$ Laboratório de Engenharia Agrícola, CCTA/UENF, Campos dos Goytacazes-RJ, Brasil, gravina@uenf.br

${ }_{4}^{4}$ Faculdade de Agronomia e Medicina Veterinária, UNB, Brasília-DF, Brasil, narasouza@unb.br

${ }_{5}^{5}$ Departamento de planejamento e políticas agrícolas, CCA/UFPI, Teresina-PI, Brasil, aecio@ufpi.br
} 


\section{Introdução}

O surgimento de cultivares de soja adaptadas às regiões de baixas latitudes promoveu o aproveitamento de áreas inexploradas, comumente chamadas de cerrado (GUARESCHI et al., 2008; PALUDZYSZYN FILHO et al., 1993). Nessas áreas, apesar de apresentarem solos com baixa fertilidade química, as condições de relevo e clima são extremamente adequadas ao cultivo (OLIVEIRA JÚNIOR et al., 2008).

A soja (Glycine max (L.) Merrill) cultivada no cerrado da microrregião do Alto Médio Gurguéia, ao Sul do estado do Piauí, teve seu desenvolvimento iniciado na década de 80 . O fortalecimento dos incentivos econômicos e a perspectiva de construção de corredores viários de exportação, na década de 90, destinados ao escoamento da produção aos grandes portos do Nordeste, especialmente ao complexo portuário de Itaqui/Ponta da Madeira, em São Luis (MA), propiciaram o aumento de novas áreas de cultivo nessa região (ARAÚJO, 2006). Na safra 2007/2008 a área cultivada com soja no Piauí alcançou o patamar de 253.700 ha, atingindo uma produtividade média de $3.240 \mathrm{~kg} \mathrm{ha}^{-1}$ (CONAB, 2008).

Os solos sob vegetação de cerrado apresentam elevada acidez, alta saturação de alumínio e baixa saturação de bases (SILVEIRA et al., 2000; WATANABE et al., 2005). No caso do fósforo, além de se encontrar em baixas concentrações nesses solos, sua disponibilidade para as plantas depende das reações de adsorção pelos óxidos e de precipitação com ferro e alumínio (BEDIN et al., 2003; NOVAIS; SMYTH, 1999; SILVA et al., 2007). Nestes solos, a maior parte do fósforo se encontra na forma de $\mathrm{P}$ não lábil, necessitando aumentar a fração do fósforo disponível para as plantas. Dobermann et al. (2002), observaram aumento da proporção das frações mais lábeis de $\mathrm{P}$ inorgânico à medida que foi adicionado fósforo ao solo, por meio da aplicação de adubos minerais solúveis. Segundo os mesmos autores, isto ocorreu, possivelmente devido à saturação de sítios de adsorção. A adição de fertilizantes pouco solúveis, como fosfatos naturais, pouco contribuíram para o aumento das frações de $\mathrm{P}$ lábil.

Segundo Piaia et al. (2002), Corrêa et al. (2004), Santos e Kliemann (2005), Oliveira Júnior et al. (2008) e Valadão Júnior et al. (2008) dos macronutrientes essenciais às plantas, o fósforo é o elemento que limita mais freqüentemente a produção das culturas na região dos cerrados. Sem o fósforo, a produtividade da cultura da soja é baixa, há redução no porte da planta e na altura de inserção das primeiras vagens (TANAKA; MASCARENHAS, 1992; VENTIMIGLIA et al., 1999).

Um bom suprimento de fósforo para a planta, por outro lado, promove incrementos significativos na produção de soja, em áreas de cerrado, mesmo no primeiro ano de cultivo (ARAÚJO et al., 2005).

Estudos com fósforo, em condições de campo e em solos de cerrado, foram conduzidos, em sua maioria, nas regiões Sudeste e Centro-Oeste (COUTINHO et al., 1991; MOTOMIYA et al., 2004). Entretanto, não se tem relatos de estudos desta natureza, em condições de campo, no Cerrado da Microrregião do Alto Médio Gurguéia. Não há parâmetros de adubação fosfatada para esta microrregião, haja vista que do início da abertura deste cerrado até os dias atuais utilizam-se de parâmetros técnicos empregados nos cerrados do Sudoeste da Bahia. Segundo Sediyama et al. (1996) os resultados de adubação não devem ser extrapolados para ambientes diferentes do experimental. Mudanças no solo, clima ou variedade, muda também a aplicação de nutrientes a nível econômico (TERUEL et al., 2001) e, daí a necessidade de se conduzir testes regionais de adubação.

Este trabalho teve por objetivo avaliar algumas características biométricas e o rendimento de grãos de soja cultivada no cerrado da microrregião do Alto Médio Gurguéia, quando submetida a diferentes níveis de adubação fosfatada.

\section{Material e métodos}

O ensaio foi conduzido na Serra do Quilombo, em área da Fazenda São Marcos, município de GilbuésPI, no período de dezembro de 2007 a abril de 2008. A área experimental encontra-se a $481 \mathrm{~m}$ de altitude, latitude 9'49'54' 'S e longitude 45'20'38' 'W. Esta foi desmatada em 2005 e cultivada com arroz na safra 2005/2006, entretanto nenhuma correção da acidez e/ou aplicação de fontes de fósforo foram realizadas.

A análise textural do solo, na camada de $0-20 \mathrm{~cm}$ apresentou $230 \mathrm{~g} \mathrm{~kg}^{-1}$ de argila, $100 \mathrm{~g} \mathrm{~kg}^{-1}$ de silte, $670 \mathrm{~g} \mathrm{~kg}^{-1}$ de areia e $23 \mathrm{~g} \mathrm{~kg}^{-1}$ de matéria orgânica. As características químicas são apresentadas na Tabela 1.

Tabela 1 - Características químicas da área experimental (0-20 cm) antes da instalação do ensaio. Gilbués-PI, UFPI, 2009

\begin{tabular}{|c|c|c|c|c|c|c|c|c|}
\hline \multirow{2}{*}{$\mathrm{pH}\left(\mathrm{CaCl}_{2}\right)$} & $\mathrm{P}$ (Melich) & $\mathrm{K}$ & $\mathrm{Ca}$ & $\mathrm{Mg}$ & $\mathrm{Al}$ & $\mathrm{H}+\mathrm{Al}$ & $\mathrm{m}$ & $\mathrm{V}$ \\
\hline & \multicolumn{2}{|c|}{$\mathrm{mg} \mathrm{dm}^{-3}$} & \multicolumn{4}{|c|}{$\mathrm{cmol}_{\mathrm{c}} \mathrm{dm}^{-3}$} & \multicolumn{2}{|c|}{$\%$} \\
\hline 3,8 & 6 & 72 & 0,3 & 0,1 & 1,0 & 7,6 & 71 & 7 \\
\hline
\end{tabular}


Para o cálculo da necessidade de calagem, foi utilizado o método de saturação de bases (CFSEMG, 1999), objetivando uma saturação de 50\%. Fez-se a correção, três meses antes da semeadura, com calcário (PRNT 88\%, 31,5\% $\mathrm{CaO}$ e 17,5\% $\mathrm{MgO}$ ).

$\mathrm{O}$ delineamento experimental utilizado foi $\mathrm{o}$ de blocos casualizados com quatro repetições. Os tratamentos consistiram de seis doses de fósforo $(0$; $40 ; 60 ; 100 ; 120$ e $140 \mathrm{~kg} \mathrm{ha}^{-1}$ de $\mathrm{P}_{2} \mathrm{O}_{5}$ ), na forma de superfosfato triplo aplicado ao lado da linha de plantio. As doses foram aplicadas na cultivar Msoy 9350, a qual possui ciclo tardio e está adaptada às condições edafoclimáticas locais, sendo a variedade mais cultivada na maioria das propriedades da região.

A unidade experimental foi composta por sete fileiras de 5,0 $\mathrm{m}$ de comprimento, com espaçamento de $0,45 \mathrm{~m}$, com 10 plantas por metro linear conforme especificação da cultivar, perfazendo uma população de 222.222 plantas ha ${ }^{-1}$. A área útil foi representada pelas três fileiras centrais de cada parcela, excluindo-se as plantas na extremidade $(1 \mathrm{~m})$ das fileiras.

As sementes foram tratadas com Standak na dosagem de $200 \mathrm{~mL} 100 \mathrm{~kg}^{-1}$ de sementes e inoculadas com Bradyrhizobium japonicum utilizando inoculante líquido Cell Tech HC, na dosagem de $300 \mathrm{~mL} \mathrm{ha}^{-1}$.

Durante todo o ciclo da cultura o controle de plantas daninhas, pragas e doenças foi realizado mediante incidência, com uso de produtos recomendados para a cultura.

As variáveis analisadas foram: altura de plantas, altura de inserção da primeira vagem e rendimento de grãos.

A altura de plantas e de inserção da primeira vagem foram quantificadas, uma semana após atingido o estádio R8, medindo-se com auxilio de uma trena milimetrada 10 plantas dentro da área útil. Sendo a altura das plantas medida a partir da superfície do solo até a extremidade da haste principal e a altura de inserção da primeira vagem a partir da superfície do solo até a inserção da primeira vagem.

O rendimento de grãos foi contabilizado em $\mathrm{kg} \mathrm{ha}^{-1}$ com um percentual de $13 \%$ de umidade.
Os dados foram submetidos aos testes preliminares para verificação da normalidade e homogeneidade de variância dos mesmos, aos testes de Lilliefors e teste de Bartlett, respectivamente. Posteriormente, os dados foram submetidos à análise de variância com regressão polinomial.

Para auxiliar na escolha do modelo, foi considerada a significância dos coeficientes da equação de regressão ajustada, testados pelo teste " $t$ " de Student, bem como os valores do coeficiente de determinação $\left(\mathrm{R}^{2}\right)$ associado a cada modelo de regressão.

As análises estatísticas foram realizadas com o auxílio do aplicativo computacional SAEG (Sistema para Análises estatísticas e Genéticas), versão 8.0, desenvolvido pela FUNARBE, da Universidade Federal de Viçosa - UFV, Viçosa-MG.

\section{Resultados e discussão}

Observa-se pelo teste "F" (Tabela 2) que não houve significância para a altura de inserção da primeira vagem, sendo altamente significativo para as demais características. Isso mostra que houve efeito da adubação fosfatada sobre a altura de plantas e rendimento de grãos, mas não afetou a altura de inserção da primeira vagem. Rosolem e Tavares (2006) estudando os sintomas de deficiência de fósforo (P) em soja verificaram que houve diferença significativa para os tratamentos com e sem fósforo, em várias características estudadas, dentre elas a produtividade da soja. Os mesmos autores inferiram que a deficiência de $\mathrm{P}$ prejudicou basicamente a formação de vagens e que as plantas de soja foram sensíveis à deficiência de fósforo após o florescimento, particularmente no pegamento de vagens, com maior percentagem de abscisão.

A altura máxima estimada das plantas foi de $56,69 \mathrm{~cm}$, sendo a dose de $95,60 \mathrm{~kg} \mathrm{ha}^{-1}$ de $\mathrm{P}_{2} \mathrm{O}_{5}$ aquela que promoveu este ponto de máxima altura (Figura 1). Esse resultado está de acordo com os encontrados por Valadão Júnior et al. (2008), os quais também encontraram um modelo quadrático na resposta da altura de plantas de soja

Tabela 2 - Quadrados médios, valores de "F"das análises de variância e sua significância para o efeito das doses de fósforo sobre os caracteres altura de plantas, altura de inserção da primeira vagem e rendimento de grãos. Gilbués-PI, UFPI, 2009

\begin{tabular}{ccccc}
\hline Fontes de variação & Quadrados médios & Valores de "F" & Significância & Coeficiente de variação (\%) \\
\hline Altura de Plantas & 350,59 & 6,94 & 0,0000 & 13,11 \\
Altura primeira vagem & 24,99 & 0,25 & 0,9405 & 23,91 \\
Rendimento de grãos & $6.566 .577,00$ & 10,84 & 0,0000 & 33,66 \\
\hline
\end{tabular}


submetidas a cinco níveis de fósforo. $\mathrm{O}$ valor de altura de planta, encontrado no presente ensaio, ficou dentro do recomendado por Sediyama et al. (2005), os quais citam que a altura mínima desejável para a colheita mecanizada em solos de topografia plana está em torno de 50 a $60 \mathrm{~cm}$.

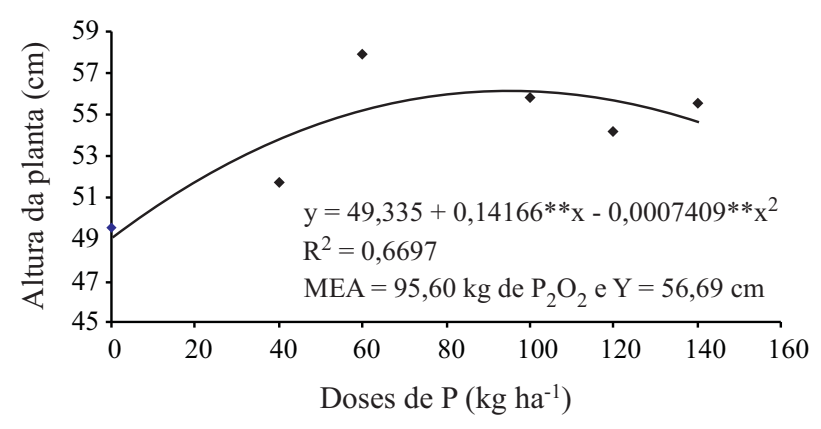

Figura 1 - Altura média de plantas de soja em função de diferentes doses de fósforo. ${ }^{*}$ Significativo a $1 \%$ de probabilidade, pelo teste " $t$ " de Student. Gilbués-PI, UFPI, 2009

Na Figura 2, observa-se que os níveis de fósforo aplicados no solo não promoveram incremento significativo na altura de inserção da primeira vagem. Não houve regressão significativa ao nível de $5 \%$ de probabilidade, indicando que a inclinação da reta não difere de zero e que não houve aumento dessa característica com o aumento das doses de $\mathrm{P}$ aplicadas no solo. A média de altura de inserção da primeira vagem encontrada neste trabalho foi de $10,64 \mathrm{~cm}$. Além da regressão linear não significativa, a amplitude de variação desta característica foi muito pequena (apenas 0,5 cm), variando de 10,6 a 11,1 cm. Tais resultados encontram-se dentro do recomendado por Sediyama et al. (2005), para terrenos planos, que segundo os autores varia de 10 a $11 \mathrm{~cm}$ acima da superfície do solo.

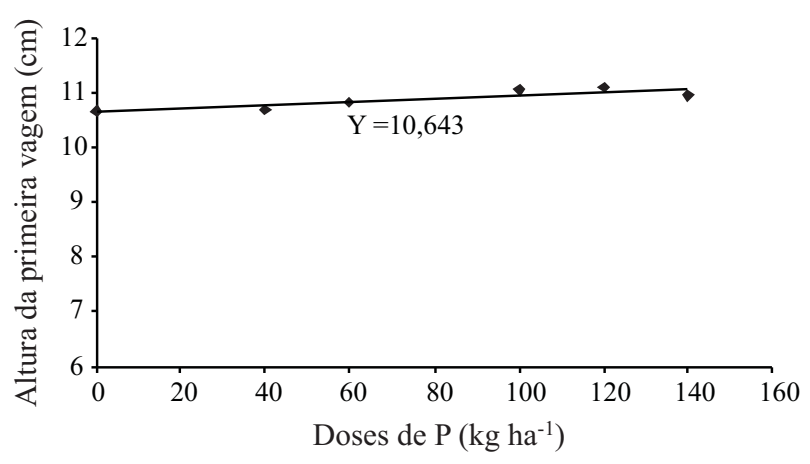

Figura 2 - Altura de inserção da primeira vagem de soja em função de doses de fósforo. Gilbués-PI, UFPI, 2009
Este resultado também é concordante com aqueles encontrados por Valadão Júnior et al. (2008), os quais não observaram influência dos níveis de fósforo sobre a altura de inserção da primeira vagem. De acordo com Rezende et al. (2005), apesar de o fósforo ser exigido durante todo o ciclo da cultura, apenas $60 \%$ do total é absorvido após o florescimento (estádio R1); dessa forma a altura de inserção da primeira vagem já foi definida, não tendo, portanto, influência dos níveis de fósforo sobre a altura de inserção da primeira vagem.

A altura de inserção da primeira vagem é uma característica importante por estar relacionada à colheita mecanizada (LANA et al., 2003).

$\mathrm{O}$ rendimento estimado de grãos de soja $\left(\mathrm{kg} \mathrm{ha}^{-1}\right)$ apresentou uma resposta quadrática às doses de fósforo aplicadas (Figura 3). A partir do modelo de regressão adotado verificou-se que o rendimento de máxima eficiência agronômica foi de $2.614 \mathrm{~kg} \mathrm{ha}^{-1}$, obtido com a dose de 94,8 $\mathrm{kg} \mathrm{ha}^{-1}$ de $\mathrm{P}_{2} \mathrm{O}_{5}$.

Estes resultados estão de acordo com aqueles obtidos por Novais e Smyth (1999). Segundo esses autores, a recomendação média de fósforo para culturas anuais, em solos com baixos teores de "P-disponível" varia de 90 a $120 \mathrm{~kg} \mathrm{ha}^{-1}$ de $\mathrm{P}_{2} \mathrm{O}_{5}$. Entretanto, com os sucessivos cultivos numa mesma área, essa recomendação tende a aumentar, é o que reportam Gianluppi et al. (2000), sugerindo uso de pelo menos $120 \mathrm{~kg} \mathrm{ha}^{-1}$ de $\mathrm{P}_{2} \mathrm{O}_{5}$.

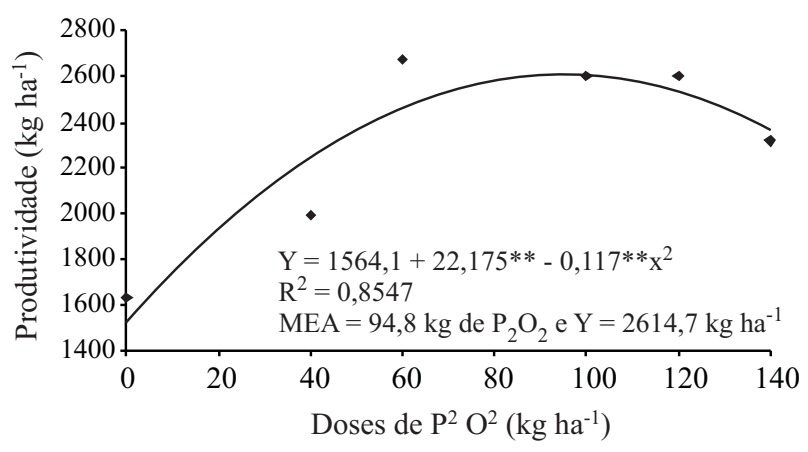

Figura 3 - Rendimento de grãos de soja em função das doses de adubação fosfatada. MEA: máxima eficiência agronômica. ** significativo a $1 \%$ de probabilidade, pelo teste "t" de Student. Gilbués-PI, UFPI, 2009

Schlindwein e Giannello (2005) também encontraram resposta quadrática quanto ao rendimento de grãos de soja à aplicação de doses de $\mathrm{P}$, em solos de cerrado. Respostas a doses muito altas de P são comuns em solos com baixos teores de fósforo disponível. Esses valores podem ser explicados pelo fato da resposta da cultura ao 
uso de fertilizantes dependerem do estado de fertilidade do solo. Logicamente, solos de baixa fertilidade apresentam alta probabilidade de resposta ao uso de nutrientes.

\section{Conclusões}

1. As alturas das plantas de soja apresentaram resposta quadrática às doses de fósforo aplicadas no solo, sendo que a altura máxima estimada pelo modelo de regressão foi de $56,69 \mathrm{~cm}$, obtida com a dose de $95,60 \mathrm{~kg} \mathrm{ha}^{-1}$ de $\mathrm{P}_{2} \mathrm{O}_{5}$.

2. A altura de inserção da primeira vagem de soja não foi influenciada pelas doses de fósforo aplicadas e sua média estimada foi de $10,64 \mathrm{~cm}$.

3. O rendimento de grãos de soja apresenta curva de resposta quadrática à adubação fosfatada. A produtividade máxima estimada foi de $2.614,7 \mathrm{~kg} \mathrm{ha}^{-1}$ de grãos de soja, obtida com a dose de $94,8 \mathrm{~kg}$ de $\mathrm{P}_{2} \mathrm{O}_{5}$.

\section{Referências}

ARAÚJO, M. R. S. Expansão da fronteira agrícola nos cerrados piauienses, (des)territorialização e os desafios para o desenvolvimento territorial: o caso do município de bom Jesus. 2006. 188 f. Dissertação (Mestrado em Desenvolvimento e Meio Ambiente) - Universidade Federal do Piauí, Teresina.

ARAÚJO, W. F.; SAMPAIO, R. A.; MEDEIROS, R. D. Resposta de cultivares de soja à adubação fosfatada. Revista Ciência Agronômica, Fortaleza, v. 36, n. 02, p. 129-134, 2005.

BEDIN, I. et al. Fertilizantes fosfatados e produção de soja em solos com diferentes capacidades tampão de fosfato. Revista Brasileira de Ciência do Solo, v. 27, p. 639-646, 2003.

COMPANHIA NACIONAL DE ABASTECIMENTO (CONAB). Acompanhamento da safra brasileira: grãos safra 2007/2008: décimo primeiro levantamento: agosto de 2008. Brasília: Conab, 2008. Disponível em: <http://www.conab. gov.br/conabweb/download/safra/11_levantamento_ out2008.pdf> Acesso em: 23 set. 2008.

CORRÊA, J. C; MAUAD, M; ROSOLEM, C. A. Fósforo no solo e desenvolvimento de soja influenciados pela adubação fosfatada e cobertura vegetal. Pesquisa Agropecuária Brasileira, v. 39, n. 12, p. 1231-1237, 2004.

COUTINHO, E.L.M. et al. Eficiência agronômica de fertilizantes fosfatados para a cultura da soja. Pesquisa Agropecuária Brasileira, v. 26, n. 09, p. 1393-1399, 1991.

DOBERMANN, A.; GEORGE, T.; THEVS, N. Phosphorus fertilizer effects on soil phosphorus pools in acid upland soils. Soil Science Society American Journal, v. 66, n. 02, p. 652-660, 2002.

GIANLUPPI, D.; GIANLUPPI, V.; SMIDERLE,O. S. Recomendações técnicas para o cultivo da soja nos cerrados de Roraima. Boa Vista: Embrapa Roraima, 2000. 35 p. (Circular Técnica).

GUARESCHI, R. F. et al. Adubação fosfatada e potássica na semeadura e a lanço antecipada na cultura da soja cultivada em solo de Cerrado. Semina: Ciências Agrárias, v. 29, n. 04, p. 769-774, 2008.

LANA, R. M. Q. et al. Adubação superficial com fósforo e potássio para a soja em diferentes épocas em pré-semeadura na instalação do sistema de plantio direto. Scientia Agraria, v. 04, n. 01-02, p. 53-60, 2003.

MOTOMIYA, W.R. et al. Métodos de aplicação de fosfato na soja em plantio direto. Pesquisa Agropecuária Brasileira, v. 39, n. 04, p. 307-312, 2004.

NOVAIS, R.F.; SMYTH, T.J. Fósforo em solo e planta em condições tropicais. Viçosa: UFV, 1999. 399p.

OLIVEIRA JUNIOR, A.; PROCHNOW, L. I; KLEPKER, D. Eficiência agronômica de fosfato natural reativo na cultura da soja. Pesquisa Agropecuária Brasileira, v. 43, n. 05, p. 623-631, 2008.

PALUDZYSZYN FILHO, E.; KIIHL, R.A.S.; ALMEIDA, L.A. Desenvolvimento de cultivares de soja na região Norte e Nordeste do Brasil. In: SIMPÓSIO SOBRE CULTURA DA SOJA NOS CERRADOS, 1992, Uberaba. Anais... Piracicaba: POTAFOS, 1993. p. 255-265.

PIAIA, F. L. et al. Eficiência da adubação fosfatada com diferentes fontes e saturações por bases na cultura da soja (Glycine $\max$ (L.) Merrill). Ciência e Agrotecnologia, v. 26, n. 03, p. 488-499, 2002.

REZENDE, P. M. et al. Adubação foliar. I. Épocas de aplicação de fósforo na cultura da soja. Ciência e Agrotecnologia, v. 29, n. 06, p. $1105-1111,2005$.

RIBEIRO, Antonio Carlos; GUIMARÃES, Paulo Tácito; ALVAREZ, Victor Hugo. Recomendações para o uso de corretivos e fertilizantes em Minas Gerais, $5^{\text {a }}$ aproximação. Viçosa: Comissão de Fertilidade do Solo do Estado de Minas Gerais, 1999. 359 p.

ROSOLEM, C. A.; TAVARES, C. A. Sintomas de deficiência tardia de fósforo em soja. Revista Brasileira de Ciência do Solo, v. 30, n. 02, p. 385-389, 2006.

SANTOS, E. A.; KLIEMANN, H. J. Disponibilidade de fósforo de fosfatos naturais em solos de cerrado e sua avaliação por extratores químicos. Pesquisa Agropecuária Tropical, v. 35, n. 02, p. 139-146, 2005.

SCHLINDWEIN, J. A.; GIANELlO, C. Doses de Máxima Eficiência Econômica de fósforo e potássio para culturas cultivadas no sistema de Plantio Direto. Revista Plantio Direto, n. 85, p. 20-25, 2005.

SEDIYAMA, T. et al. Cultura da soja (I parte). Viçosa: UFV, 1996, 96p.

SEDIYAMA, T.; TEIXEIRA, R. C.; REIS, M. S. Melhoramento da soja. In: BORÉM A. Melhoramento de espécies cultivadas. Viçosa: Editora UFV, 2005. p. 553-603. 
SILVA, M. O. et al. Desempenho da mucuna preta quando adubada com diferentes tipos de fosfato. Revista de Biologia e Ciências da Terra, v. 07, n. 01, p. 127-132, 2007.

SILVEIRA, P. M. et al. Amostragem e variabilidade espacial de características químicas de um latossolo submetido a diferentes sistemas de preparo. Revista Brasileira de Ciência do Solo, Campinas, v. 35, n. 10, p. 2057-2064, 2000.

TANAKA, R. T.; MASCARENHAS, H. A. A. Soja, nutrição, correção do solo e adubação. Campinas: Fundação Cargill, 1992. 60 p.

TERUEL, D. A.et al. Alterações estruturais do sistema radicular de soja em resposta à disponibilidade de fósforo no solo. Scientia Agricola, v. 58, n. 01, p. 55-60, 2001
VALADÃO JÚNIOR, D. D. et al. Adubação fosfatada na cultura da soja em Rondônia. Scientia Agraria, v. 09, n. 03, p. $369-375,2008$.

VENTIMIGLiA, L. A. et al. Potencial de rendimento da soja em razão da disponibilidade de fósforo no solo e dos espaçamentos. Pesquisa Agropecuária Brasileira, v. 34, n. 02, p. 195-199, 1999.

WATANABE, R. T. et al. M. Produtividade da cultura da soja em função da densidade populacional e da porcentagem de cátions ( $\mathrm{Ca}, \mathrm{Mg}$ e $\mathrm{K}$ ) no complexo sortivo do solo. Semina: Ciências Agrárias, v. 26, n. 04, p. 477-484, 2005. 